\title{
Effects of word length on young children's memory performance
}

\author{
MIKI YUZAWA \\ Hiroshima University, Higashi Hiroshima, Japan
}

\begin{abstract}
The standard working model that accounts for word length effects in young children has been questioned. This study explored two hypotheses suggested by Gathercole and Hitch (1993). In three experiments with serial recall tasks, the word presentation interval was adjusted so that participants could repeat both long and short words subvocally the same number of times in the intervals between the words presented. As a result, among children from 3 to 6 years of age, the word length effect was significantly reduced, whereas the same manipulation of the word presentation interval did not affect the word length effect in adults. These results suggest that the word length effects in young children reflect the process of retaining auditory information in the interval between presentations as well as readout of the phonological representation.
\end{abstract}

The phonological loop is a component of the working memory model introduced by Baddeley and Hitch (1974). It has proved highly successful in characterizing the nature of the retention of auditory information over short periods of time. The loop comprises a phonological store and a rehearsal process. The phonological store holds information in a phonological form, and the rehearsal process serves to maintain decaying representations in the phonological store. Since the trace in the phonological store decays at a constant rate, more words can be maintained if the words are rehearsed quickly. The effects of word length, phonological similarity, and articulatory suppression are regarded as evidence for these two subsystems (see, e.g., Baddeley, 1986, 1990).

The word length effect is that the recall of long words is worse than that of short words (Baddeley, Thomson, \& Buchanan, 1975) because long words take longer to articulate during rehearsal. Articulatory suppression effects indicate that the capacity of the phonological loop diminishes with irrelevant articulation or articulatory suppression, which prevents the participant from rehearsal processing (Murray, 1967). Finally, phonological similarity effects indicate that the recall of phonologically similar words is worse than that of phonologically dissimilar words (Conrad \& Hull, 1964) owing to poor recall because of confusion between similar memory traces in the phonological store.

Word length effects have been studied developmentally to examine whether young children use rehearsal for au-

I am grateful to my supervisor, Akira Yamazaki, for his comments and encouragement. I thank particularly Masamichi Yuzawa for his help in the preparation of this paper. I also thank Peter Graf, Susan E. Gathercole, and an anonymous reviewer for their helpful comments on an earlier version of this paper. Correspondence should be addressed to M. Yuzawa, 4-402, 2-365, Kagamiyama, Higashi Hiroshima 739-0046, Japan (e-mail: mkamei@ hiroshima-u.ac.jp). ditory information (e.g., Conrad, 1971; Hitch, Halliday, Dodd, \& Littler, 1989; Hulme, 1984; Hulme, Thomson, Muir, \& Lawrence, 1984). The emergence of word length effects depends on the mode of presentation. With a visually presented list, children do not show word length effects until after about 7 or 8 years of age (Allik \& Siegel, 1976; Hitch \& Halliday, 1983; Hitch, Halliday, Dodd, \& Littler, 1989), whereas with auditory presentation even 4-year-old children show word length effects (Hitch \& Halliday, 1983; Hitch, Halliday, Dodd, \& Littler, 1989; Hitch, Halliday, \& Littler, 1989; Hitch, Halliday, Schaafstal, \& Heffernan, 1991; Hulme et al., 1984; Hulme \& Tordoff, 1989). In terms of the working memory model, the mechanisms of the articulatory loop system must therefore be in place by about age 4 , since 4 -year-old children show word length effects with auditory presentation. The mechanisms must be much the same in older children and adults, but young children cannot translate visual information into auditory information.

However, this standard working model of short-term memory development has been challenged by results showing that the effects of articulatory suppression and phonological similarity, and the relationship between the articulation rate and memory span, are all inconsistent in young children (Gathercole \& Adams, 1994; Gathercole, Adams, \& Hitch, 1994; Gathercole \& Hitch, 1993; Henry, 1991a; Hitch, 1990). For example, in studies that focused on individual differences in articulation rates and memory spans, the articulation rates of 4-year-old children were found to have no correlation with their memory span, although the relationship was positive in older children (Gathercole \& Adams, 1994; Gathercole et al., 1994). Moreover, it was found that 5-year-old children were not impaired by articulatory suppression, which is believed to prevent rehearsal (Henry, 1991a), although there is some evidence to the contrary (Hitch, 1990). It has therefore been suggested that word length effects in young chil- 
dren might not reflect the same sophisticated rehearsal processes that are present in older children and adults.

Gathercole and Hitch (1993) suggested two possible alternatives to the standard explanation for word length effects in young children. One hypothesis is that these effects might reflect the readout process that maps the phonological representations in the phonological store of the articulatory loop serially onto abstract articulatory gestures. In this process of serial conversion of phonological units into corresponding remote articulatory commands, long words might suffer more decay as "unread" representations that remain in the phonological store, because the process is lengthier for long words than it is for short words. This hypothesis is supported by the results of Henry (1991b).

Henry (1991b) used probe tasks to examine the effect of output processing on word length effects. In these probe tasks, an experimenter named each item and simultaneously placed the appropriate picture card with its face down on a table. Recall was probed in one of two waysusing a spatial probe or an auditory probe. In the spatial probe task, the experimenter pointed to one card and the participant named the item on the card; in the auditory probe task, the experimenter stated one of the words and the participant pointed to the card corresponding to that word. The participants were not required to recall the full memory sequence aloud in either task. Consequently, 5year-old children did not show word length effects, whereas 7-year-olds did. In contrast, when a more conventional task was used, involving spoken serial output at recall, both groups of children showed word length effects.

Since young children show the word length effect in serial, but not probed, spatial recall, however, Gathercole and Hitch (1993) speculated that this might be because young children adopt a spatial encoding strategy in response to the location probe. If this speculation were correct, then Henry's (1991b) finding would not provide evidence for the hypothesis that the word length effect in young children reflects the readout process of the phonological representations in the phonological store.

Another hypothesis on the cause of word length effects is that young children might employ a more rudimentary form of rehearsal than that of older children and adults. A study that asked children to "think aloud" for a memory task involving spoken words showed that 4-yearold children tended to repeat single words in isolation and that cumulative rehearsal did not become pervasive until about 9 or 10 years of age (Guttentag, Ornstein, \& Siemens, 1987). Development of rehearsal might be divided into three stages: overt repetition, simple subvocal repetition, and cumulative rehearsal. Children up to 2 or 3 years of age repeat a word aloud when attempting to remember it, exploiting direct links between its perceived phonologicalstructure and the corresponding articulatory gestures. The articulatory gestures cannot, however, be inhibited. In the next stage, simple subvocal rehearsal, children learn to exploit the articulatory gestures associated with the spoken word, without actually executing them.
Finally, there is the covert cumulative rehearsal used by older children and adults. Specifically, each of the presented words in a sequence is rehearsed in the interval before the next word is presented. When the next word arrives, it too is incorporated into the rehearsal sequence.

In the second stage, simple subvocal repetition might be sufficient to yield word length effects in 4- or 5-yearold children, since they might not have sufficient time to subvocally "repeat" a long word during the presentation of a memory list. In previous studies, the presentation time for both short and long words has been constant (e.g., $2 \mathrm{sec}$ ). Short words might be favored because the children are able to repeat the short words more times than the long words, given the same period. For example, in the interval between the presentation of two words, children might be able to repeat short words twice, but long words only once, and more repetitions of a word would produce a more intense memory trace for the word.

In this study, both the readout process hypothesis and the simple repetition hypothesis were examined. Since the two hypotheses are not necessarily mutually exclusive, there are three possibilities. First, that word length effects in young children reflect only the readout process; second, that word length effects reflect only the process of retaining auditory information in the word presentation interval; and third, that word length effects reflect both processes. Experiments 1 and 2 tested these three possibilities by manipulating the word presentation interval in a serial recall task. In both experiments, children from 3 to 6 years of age performed serial recall tasks under two conditions. In the experimental condition, the word presentation interval was adjusted so that children could subvocally repeat both long and short words the same number of times in the interval. In the control condition, the word presentation interval was constant across short and long word tasks, as in previous studies. If word length effects in young children reflect only the process of retaining auditory information in the word presentation interval, then the effect should be evident under the control condition but not under the experimental condition. On the other hand, if the process of reading out phonological representations when asked to recall words in a serial order explains the word length effect, the effect should also exist under the experimental condition. Moreover, if the effect reflects the process of retaining auditory information as well as the readout process, then the effect might be greater under the experimental condition than under the control condition.

\section{EXPERIMENT 1}

\section{Method}

Design. The stimulus presentation interval (control condition vs. experiment condition) and the type of word (short vs. long) were varied within participants. Participants were given four blocks of trials. There were four different block orders: (1) short-control, longcontrol, short-experimental, long-experimental; (2) long-control, short-control, long-experimental, short-experimental; (3) shortexperimental, long-experimental, short-control, long-control; and 
(4) long-experimental, short-experimental, long-control, shortcontrol. Each participant was randomly assigned to one of the four different orders.

Participants. Nineteen 3- and 4-year-olds (mean age $=4.41$ years, range $=3.75-4.75$ ) participated in Experiment 1 . The children attended a nursery school in a middle-sized city in Japan. The children were all Japanese and from predominantly middle-class families. The numbers of male and female participants were approximately the same.

Stimulus set. Vocabulary tests were conducted to choose stimuli that were familiar to young Japanese children. The participants in these vocabulary tests were not those participating in Experiment 1 or 2 . First, a standardized set of 260 pictures, normalized for name agreement, image agreement, familiarity, and visual complexity (Snodgrass \& Vanderwart, 1980), was shown to 4 university students. Those pictures given the same name by at least three out of the four were selected. Second, sixteen 3- and 4-year-olds (mean age $=4.5$ years, range $=3.9-4.4)$ were asked to name these stimuli. Words consisting of two moras (the mora is an indispensable unit in Japanese, akin to the syllable in English) were regarded as short words, and words of four moras were regarded as long. Five short words and five long words for living things and manmade objects ( 20 words in total) were selected for the stimulus set used in Experiments 1 and 2 from the items that children were most often able to name (Appendix A). ${ }^{1}$ Medium words of three moras were chosen as stimuli for practice tasks. The mean percentages of correct responses were $91.4 \%$ and $89.0 \%$ for short and long words, respectively. The difference was not statistically significant $[t(15)=$ 0.62 , n.s.].

Sets of words comprising from 1 to 6 different words were selected randomly and repeatedly from among the 10 short words or the 10 long words. Four different sets of words were used in a trial of each span (1-6), and 8 sets of short words and 8 sets of long words were prepared for four blocks of trials. There were four different patterns in which these 16 sets were assigned to four blocks of trials (i.e., the same 4 sets of short or long words were assigned to the experimental condition in two patterns, and to the control condition in the other two patterns), and approximately one quarter of the participants each were given one of the four patterns.

Interval of stimulus presentation. To determine the interval time (from the end of one word to the start of the next) for stimulus presentation under the experimental and control conditions, the articulation time for each of 10 short and 10 long words was measured for all the participants. The participants sat in front of a computer and were asked to clearly repeat the words, presented at 2-sec intervals through a headset. As soon as the child finished saying each word, the experimenter pushed a button. The mean articulation times were 1.20 (range $=1.1-1.3$ ) sec for short words and 1.55 (range $=1.4-1.7$ ) sec for long words. For the control condition, the interval time was therefore set at $2.6 \mathrm{sec}$, since in this interval participants could repeat short words twice, but long words only once. For the experimental condition, the interval was $3.1 \mathrm{sec}$, giving participants sufficient time to repeat both short and long words twice on average, but neither of them three times.

Procedure. Children were tested individually, in a single session that lasted approximately $15 \mathrm{~min}$. First, children were shown all 20 pictures in the stimuli set one at a time and asked to name them. Errors were corrected, and children were then given the pictures again to ensure that they could name them correctly. After success with words of three moras in practice trials, each participant was given four blocks of trials.

The participant sat in front of a computer. A bear appeared on the computer screen, and below the bear drawings of buttons arranged in a line were seen on the screen. The bear said, "Let's play the guessing names game. I will push the buttons and you will hear a list of names. Please teach me the names in the same order." Then, the bear disappeared, and as a button on the screen changed shape, a stimulus word was presented in an auditory form. These stimulus words were from one of the four sets of words prepared for individual children. After the presentation, the bear reappeared and asked the participant to tell it the names in the same order. A block of trials started with a trial with a single word. If the participant correctly recalled the words in a sequence twice, the participant proceeded to the next trial, which included an additional word. The block of trials ended when the participant failed to recall the words in a sequence twice successively. The maximum number of words that a participant could recall twice was regarded as that individual's memory span.

\section{Results and Discussion}

Table 1 shows the mean memory spans for short and long words under the experimental and control conditions. A repeated measures 2 (condition: experimental or control) $\times 2$ (word length: short or long) analysis of variance (ANOVA) was conducted on the memory span. The main effect of word length was significant $[F(1,18)=5.56, p<$ $.05]$, but the main effect was qualified by the significant interaction between condition and word length $[F(1,18)=$ $5.51, p<.05]$. A test for simple main effects revealed that the difference in memory span between short and long words was significant under the control condition $[F(1,36)=10.57, p<.01]$, but not under the experimental condition $[F(1,36)=0.52$, n.s. $]$.

A similar result was obtained for the memory patterns of individual children. Three children performed better for short words than for long words under both the control and experimental conditions. Seven children performed better for short words than for long words under the control but not the experimental condition, whereas no children performed better for short words than for long words under the experimental but not the control condition. A significant difference was detected between the control and experimental conditions in the fraction of children showing the word length effect ( $p=.008$ by McNemar test).

The word length effect that was evident under the control condition diminished when the word presentation interval was adjusted so that children could repeat both long and short words the same number of times subvocally in the interval between each word. The results are congruent with the simple repetition hypothesis. On the other hand, the results do not seem to be congruent with the readout process hypothesis, suggesting that simple repetition in the word presentation interval can account for the word length effect.

However, there were limitations in the results of Experiment 1 . First, because the word length effect under the control condition was not big enough, the influence of the readout process might not have been detected. The

Table 1

Memory Span Under Experimental and Control Conditions in Experiment 1

\begin{tabular}{|c|c|c|c|c|}
\hline \multirow[b]{3}{*}{ Words } & \multicolumn{4}{|c|}{ Condition } \\
\hline & \multicolumn{2}{|c|}{ Experimental } & \multicolumn{2}{|c|}{ Control } \\
\hline & $M$ & $S D$ & $M$ & $S D$ \\
\hline Short & 2.58 & 0.59 & 2.68 & 0.65 \\
\hline Long & 2.47 & 0.50 & 2.21 & 0.69 \\
\hline
\end{tabular}

Note $-N=19$. 
small word length effect might reflect the fact that the participants were 3-and 4-year-olds. Since their memory span is relatively small, the task might not be sensitive to the difference between short words and long words. In addition, since they were only beginning to enter the stage of simple subvocal rehearsal, not all the children might have used simple subvocal rehearsal for the presented words. Second, the word presentation interval was constant across the participants, even under the experimental condition. However, because there were individual differences in articulation time, there was no guarantee that all the children could subvocally repeat both long and short words the same number of times in the interval under the experimental condition.

In consideration of these limitations, Experiment 2 was conducted to replicate and extend the results of Experiment 1. In Experiment 2, 5- and 6-year-olds participated as well as 3- and 4-year-olds, and the word presentation intervals under the experimental condition were varied according to the articulation times of individual children.

\section{EXPERIMENT 2}

\section{Method}

Design. The participants consisted of two age groups (3- and 4year-olds and 5- and 6-year-olds), and the stimulus presentation interval (control condition vs. experiment condition) and the type of word (short vs. long) were varied within participants. Participants were given four blocks of trials. There were four different block orders, as in Experiment 1, and each participant was randomly assigned to one of the four different orders.

Participants. Seventeen 3- and 4-year-olds (mean age $=4.50$ years, range $=3.25-4.83$ ) and seventeen 5 - and 6-year-olds (mean age $=6.16$ years, range $=5.67-6.83)$ participated in Experiment 2 . The children attended a nursery school different from the school in Experiment 1 but in the same middle-sized city in Japan. The children were all Japanese and from predominantly middleclass families. The numbers of male and female participants were approximately the same.

Stimulus set. The stimulus set consisted of the same five short words and five long words for living things and man-made objects as used for Experiment 1 (see Appendix A). Sets of words comprising from 1 word to 6 different words were selected randomly and repeatedly from among the 10 short words or the 10 long words. Three sets of words were used for a trial of each span (1-6), and 6 sets of short words and 6 sets of long words were prepared for four blocks of trials. There were four different patterns in which these 12 sets were assigned to four blocks of trials (i.e., the same 3 sets of short or long words were assigned to the experimental condition in two patterns, and to the control condition in the other two patterns), and approximately one quarter of the participants each received one of the four different patterns.

Interval of stimulus presentation. To determine the interval time (from the end of one word to the start of the next) for stimulus presentation under the experimental and control conditions, the articulation time for each of 10 short and 10 long words was measured for all the participants. The participants sat in front of a computer and were asked to clearly repeat the words, presented at 2-sec intervals through a headset. Each participant's responses were recorded and analyzed by a computer for articulation time. The mean articulation times were 1.10 (range $=0.9-1.2$ ) $\mathrm{sec}$ for short words and 1.50 (range $=1.4-1.8$ ) sec for long words in 3 - and 4-year-olds, and 1.02 (range $=0.9-1.1$ ) sec for short words and
1.41 (range $=1.2-1.7$ ) sec for long words in 5- and 6-year-olds. For the control condition, the interval time was therefore set at $2.5 \mathrm{sec}$ for the 3- and 4-year-olds and $2.2 \mathrm{sec}$ for the 5- and 6-year-olds, since in this interval participants could repeat short words twice, but long words only once, on average. For the experimental condition, the intervals of word presentation were made twice the mean articulation times of each child. For example, if a child's mean articulation times for short words and long words were 1.1 and $1.5 \mathrm{sec}$, respectively, the interval times for that child under the experimental condition were set at $2.2 \mathrm{sec}$ for short words and $3.0 \mathrm{sec}$ for long words.

Procedure. Children were tested individually in a single session that lasted approximately $15 \mathrm{~min}$. The procedure was almost the same as that in Experiment 1, but two changes were added: (1) in Experiment 1, drawings of buttons on the screen were used as a cue for serial recall, but such cues were deleted in Experiment 2, and (2) in Experiment 1, success in recalling the words in a sequence twice successively or failure to recall the words in a sequence twice successively were criteria to change trials, whereas in Experiment 2, children were provided with three serial recall tasks at most in one trial, because success or failure twice was the criterion to change trials.

First, children were shown all 20 pictures in the stimulus set, one at a time, and asked to name them. Errors were corrected, and children were then given the pictures again to ensure that they could name them correctly. After success with words of three moras in practice trials, each participant was given four blocks of trials.

The participant sat in front of a computer, and the examiner said, "Let's play the guessing names game. You will hear a list of names from the computer. Please teach me the names in the same order." Then, the stimulus words were presented in an auditory form. After the presentation, the participants were asked to say the names in the same order. A block of trials started with a trial with a single word. The stimulus words were selected from the three sets of words prepared for individual participants. If the participant correctly recalled the words in a sequence twice, the participant proceeded to the next trial, which included an additional word. The block of trials ended when the participant failed to recall the words in a sequence twice. The maximum number of words that a participant could recall twice was regarded as that individual's memory span.

\section{Results and Discussion}

Table 2 shows the two age groups' mean memory spans for short and long words under the experimental and control conditions. A 2 (age: 3- and 4-year-olds vs. 5and 6-year-olds) $\times 2$ (condition: experimental vs. control) $\times 2$ (word length: short vs. long) ANOVA was conducted on the memory span with condition and word length as repeated measures. The main effects of age and word length were significant $\left[F_{\mathrm{S}}(1,32)=23.00\right.$ and $\left.39.56, p<.01\right]$. The main effect of word length was qualified by the sig-

Table 2

Memory Span Under Experimental and

Control Conditions in Experiment 2

\begin{tabular}{lllll}
\hline & \multicolumn{4}{c}{ Condition } \\
\cline { 2 - 5 } Words & \multicolumn{2}{c}{ Experimental } & \multicolumn{2}{c}{ Control } \\
\cline { 2 - 5 } \cline { 3 - 4 } & $M$ & $S D$ & $M$ & $S D$ \\
\hline Short & 2.18 & 0.51 & 2.29 & 0.46 \\
Long & 2.00 & 0.69 & 1.65 & 0.59 \\
& 5 - and 4-Year-Olds $(n=17)$ & \\
Short & 3.00 & 0.49 & 3.12 & 0.68 \\
Long & 2.71 & 0.57 & 2.47 & 0.50 \\
\hline
\end{tabular}


nificant interaction between condition and word length $[F(1,32)=10.18, p<.01]$. A test for simple main effects revealed that the difference in memory span between short and long words was significant, both under the control condition $[F(1,64)=46.10, p<.01]$ and under the experimental condition $[F(1,64)=6.10, p<.05]$. In addition, it was revealed that the memory span for long words was significantly larger under the experimental condition than under the control condition $[F(1,64)=$ $11.43, p<.05]$. These results suggest that the word length effect was evident under the experimental condition as well as under the control condition, although the detrimental effect of long words was much smaller under the experimental condition.

The memory patterns of individual children provided a more straightforward result. Two 3- and 4-year-olds and six 5-and 6-year-olds performed better for short words than for long words under both control and experimental conditions. Nine 3- and 4-year-olds and seven 5and 6-year-olds performed better for short words than for long words under the control but not the experimental condition, whereas two 3- and 4-year-olds and no 5and 6-year-olds performed better for short words than for long words under the experimental but not the control condition. Significant differences were detected between the control and experimental conditions in the fraction of children showing the word length effect, both in the group of 3 - and 4-year-olds ( $p=.033$ by McNemar test) and in the group of 5- and 6-year-olds ( $p=.008$ by McNemar test).

Overall, the word length effect that was evident under the control condition decreased greatly when the word presentation interval was adjusted so that children could repeat both long and short words the same number of times subvocally in the interval between each word. The results are congruent with the simple repetition hypothesis, as in Experiment 1. On the other hand, under the experimental condition, the word length effect was still evident, which supported the readout process hypothesis as well. Concerning the reason for the difference in the results of Experiments 1 and 2, it should be noted that more children in the group of 5- and 6-year-olds showed the word length effect under the experimental condition (35\%) as well as under the control condition (76\%), in comparison with 3 - and 4 -year-olds ( $24 \%$ and $65 \%$ for the corresponding figures).

\section{EXPERIMENT 3}

The results of Experiments 1 and 2 supported both the simple repetition hypothesis and the readout process hypothesis. Before concluding that word length effects in young children reflect the process of retaining auditory information in the word presentation interval, as well as the process of reading out phonological representations, I had to confirm that manipulation of the word presentation interval does not affect word length effects in older children or adults, who use sophisticated rehearsal pro- cesses in a serial recall task. If the manipulation of word presentation interval affects the word length effects in older children or adults, the results of Experiments 1 and 2 could be attributed to processes other than retaining auditory information during the word presentation interval. In order to exclude this possibility, in Experiment 3, I administered serial recall tasks to adults in the same way as in Experiment 2.

\section{Method}

Design. The stimulus presentation interval (control condition vs. experiment condition) and the type of word (short vs. long) were varied within participants. Participants were given four blocks of trials. There were four different block orders, as in Experiments 1 and 2, and each participant was randomly assigned to one of the four different orders.

Participants. Ten graduate students at a national university in Japan participated in Experiment 3 (mean age $=25.9$ years, range $=$ 23-31). There were 3 male and 7 female participants.

Stimulus set. The stimulus set consisted of 26 short and 26 long words for living things and man-made objects (Appendix B). These words were selected from a list by Sakamoto (1984) of standard Japanese vocabulary that children from first to ninth grade are supposed to acquire, so that the short words and the long words were comparable in familiarity and importance in education.

Three sets of words were used in a trial of each span (3-6), and 6 sets of short words and 6 sets of long words were prepared for four blocks of trials. There were two different patterns in which these 12 sets were assigned to four blocks of trials (i.e., the same 3 sets of short or long words were assigned to the experimental condition in one pattern, and to the control condition in the other pattern), and half of the participants received one of the two patterns.

Interval of stimulus presentation. To determine the interval time for stimulus presentation under the experimental and control conditions, the articulation time for each of 24 short and 24 long words was measured for all the participants. The participants sat in front of a computer and were asked to clearly repeat the words, presented at 2-sec intervals through a headset. Each participant's responses were recorded and analyzed by a computer for articulation time. The mean articulation times were 0.45 (range $=0.4-0.5$ ) sec for short words and 0.66 (range $=0.6-0.8$ ) sec for long words. For the control condition, the interval time was therefore set at $1.1 \mathrm{sec}$, since in this interval participants could repeat short words twice, but long words only once, on average. For the experimental condition, the intervals of word presentation were made twice the mean articulation times of each participant, as in Experiment 2.

Procedure. Participants were tested individually in a single session that lasted approximately $10 \mathrm{~min}$. The procedure was exactly the same as that used in Experiment 2, except that they were not shown pictures of the stimulus words at the beginning of the experiment. First, participants were given practice trials with words of three moras. After these trials, participants were given four blocks of trials. A block of trials started with a trial with three words. The stimulus words were selected from the three sets of words prepared for individual participants. If the participant correctly recalled the words in a sequence twice, the participant proceeded to the next trial, which included an additional word. The block of trials ended when the participant failed to recall the words in a sequence twice. The maximum number of words that a participant could recall twice was regarded as that individual's memory span.

\section{Results and Discussion}

Table 3 shows the mean memory spans for short and long words under the experimental and control conditions. A repeated measures 2 (condition: experimental vs. con- 
Table 3

Memory Span Under Experimental and Control Conditions in Experiment 3

\begin{tabular}{|c|c|c|c|c|}
\hline \multirow[b]{3}{*}{ Words } & \multicolumn{4}{|c|}{ Condition } \\
\hline & \multicolumn{2}{|c|}{ Experimental } & \multicolumn{2}{|c|}{ Control } \\
\hline & $M$ & $S D$ & $M$ & $S D$ \\
\hline Short & 4.70 & 0.75 & 4.80 & 0.78 \\
\hline Long & 4.30 & 0.80 & 4.40 & 0.78 \\
\hline
\end{tabular}

Note $-N=10$.

trol) $\times 2$ (word length: short vs. long) ANOVA was conducted on the memory span. Only the main effect of word length was significant $[F(1,9)=7.58, p<.05]$. Neither the main effect of condition nor the interaction was significant. The results suggest that the manipulation of word presentation interval did not affect the word length effect.

A similar result was obtained for the memory patterns of individual participants. Two participants performed better for short words than for long words under both the control and experimental conditions; 3 participants performed better for short than for long words only under the control condition; and 3 participants performed better for short than for long words only under the experimental condition.

In summary, it was shown that the manipulation of word presentation interval does not affect word length effects in adults. The result excluded the possibility that the effects of the manipulation of word presentation interval on young children in Experiments 1 and 2 might be attributed to processes other than the process of retaining auditory information in the word presentation interval.

\section{GENERAL DISCUSSION}

In this study I examined two hypotheses for the cause of the word length effect. In serial recall tasks with children from 3 to 6 years of age, the word presentation interval was adjusted so that children could repeat both long and short words the same number of times subvocally in the intervals, and the word length effect was significantly reduced. This supported the simple repetition hypothesis that the word length effect should reflect the process of retaining auditory information in the word presentation interval. On the other hand, the word length effect was still evident under the experimental condition in Experiment 2, which suggested that the readout process also contributes to the word length effect in young children.

These results cannot be explained by the standard working model that word length effects in young children reflect the same sophisticated rehearsal processes as found in older children and adults. If young children engaged in the same sophisticated rehearsal processes, then the memory span should have been smaller for long words than for short words, irrespective of the presentation interval between the words. In fact, adults showed the word length effect in exactly the same way under both the experimental and control conditions, which was in sharp contrast with the results for young children.
The results of this study seem to best fit the hypothesis that young children employ a rudimentary form of rehearsal, repeating the presented word that they have just heard in the interval until the next word is presented. While previous research threw strong doubt on the standard working model for word length effects in young children (Gathercole et al., 1994; Gathercole \& Hitch, 1993; Henry, 1991a, 1991b), the exact mechanism for word length effects at this age remained unclear. The findings of this study provide new detail in the picture of verbal short-term memory in young children.

The results of this study also suggest that the word length effect in young children reflects not only the process of retaining auditory information in the word presentation interval, but also the process of reading out phonological representations when asked to recall words in a serial order. A substantial number of children performed better for short than for long words, even under the experimental condition. Compelling evidence suggests that in adults word length effects can arise simply as a consequence of the delay in recall that is introduced by employing memory items of long spoken duration (e.g., Cowan et al., 1992). It is suggested that deteriorating effects of word length during readout of the phonological representation also exist in children from 3 to 6 years of age, although the effects are small in comparison with the effect of repetition on memory strength at their age.

\section{REFERENCES}

Allik, J. P., \& Siegel, A. W. (1976). The use of the cumulative rehearsal strategy: A developmental study. Journal of Experimental Child Psychology, 21, 316-327.

BADDELEY, A. D. (1986). Working memory. Oxford: Oxford University Press, Clarendon Press.

BAdDEley, A. D. (1990). Human memory: Theory and practice. Hove, U.K.: Erlbaum.

BAdDEley, A. D., \& Hitch, G. J. (1974). Working memory. In G. H. Bower (Ed.), The psychology of learning and motivation (Vol. 8, pp. 47-90). New York: Academic Press.

Baddeley, A. D., Thomson, N., \& Buchanan, M. (1975). Word length and the structure of short-term memory. Journal of Verbal Learning \& Verbal Behavior, 14, 575-589.

Conrad, R. (1971). The chronology of development of covert speech in children. Developmental Psychology, 5, 398-405.

ConRad, R. \& Hull, A. J. (1964). Information, acoustic confusion and memory span. British Journal of Psychology, 55, 429-432.

Cowan, N., Day, L., Saults, J. S., Keller, T. A., Johnson, T., \& FLORES, L. (1992). The role of verbal output time in the effects of word length on immediate memory. Journal of Memory \& Language, 31, $1-17$.

Gathercole, S. E., \& Adams, A.-M. (1994). Children's phonological working memory: Contributions of long-term knowledge and rehearsal. Journal of Memory \& Language, 33, 672-688.

Gathercole, S. E., Adams, A.-M., \& Hitch, G. J. (1994). Do young children rehearse? An individual-differences analysis. Memory \& Cognition, 22, 201-207.

Gathercole, S. E., \& Hitch, G. J. (1993). Developmental changes in short-term memory: A revised working memory perspective. In A. F. Collins, S. E. Gathercole, M. A. Conway, \& P. E. Morris (Eds.), Theories of memory (pp. 189-210). Hove, U.K.: Erlbaum.

Guttentag, R. E., Ornstein, P. A., \& Siemens, L. (1987). Children's spontaneous rehearsal: Transitions in strategy acquisition. Cognitive Development, 2, 307-326, 
Henry, L. A. (1991a). Development of auditory memory span: The role of rehearsal. British Journal of Developmental Psychology, 9, 493-511.

Henry, L. A. (1991b). The effects of word length and phonemic similarity in young children's short-term memory. Quarterly Journal of Experimental Psychology, 43A, 35-52.

Hгтсн, G. J. (1990). Developmental fractionation of working memory. In G. Vallar \& T. Shallice (Eds.), Neuropsychological impairments of short-term memory (pp. 221-246). Cambridge: Cambridge University Press.

Hitch, G. J., \& Halliday, M. S. (1983). Working memory in children. Philosophical Transactions of the Royal Society of London: Series B, 302, 325-340.

Hitch, G. J., Halliday, M. S., Dodd, A., \& LitTler, J. E. (1989). Development of rehearsal in short-term memory: Differences between pictorial and spoken stimuli. British Journal of Developmental Psychology, 7, 347-362.

Hitch, G. J., \& Halliday, M. S., \& Littler, J. E. (1989). Item identification time and rehearsal rate as predictors of memory span in children. Quarterly Journal of Experimental Psychology, 41A, 321-337.

Hitch, G. J., Halliday, M. S., SchaAfstal, A. M., \& Heffernan, T. M. (1991). Speech, "inner speech," and the development of shortterm memory: Effects of picture-labeling on recall. Journal of Experimental Child Psychology, 51, 220-234.
Hulme, C. (1984). Developmental differences in the effects of acoustic similarity on memory span. Developmental Psychology, 20, 650-652.

Hulme, C., Thomson, N., Muir, C., \& Lawrence, A. (1984). Speech rate and the development of short-term memory span. Journal of Experimental Child Psychology, 38, 241-253.

Hulme, C., \& ToRdoff, V. (1989). Working memory development: The effects of speech rate, word length, and acoustic similarity on serial recall. Journal of Experimental Child Psychology, 47, 72-87.

Murray, D. J. (1967). The role of speech responses in short-term memory. Canadian Journal of Psychology, 21, 263-276.

SAKамото, I. (1984). New standard vocabulary of Japanese for education. Tokyo: Gakugei Tosyo.

SNOdGRAss, J. G., \& VANDERWART, M. (1980). A standardized set of 260 pictures: Norms for name agreement, image agreement, familiarity, and visual complexity. Journal of Experimental Psychology: Human Learning \& Memory, 6, 174-215.

\section{NOTE}

1. Relatively small numbers of words were used here for two reasons: (1) It is difficult to sample long Japanese words that are familiar to young children, and (2) it was necessary to reduce the range of articulation time for words of the same length in individual children.

APPENDIX A

Stimulus Set in Experiments 1 and 2

\begin{tabular}{clllll}
\hline \multirow{2}{*}{ Category } & \multicolumn{2}{c}{ Short word } & & \multicolumn{2}{c}{ Long Word } \\
\cline { 2 - 3 } \cline { 5 - 6 } Living things & Word & Meaning & & Word & Meaning \\
& Ari & Ants & & Fukurou & Owl \\
& Inu & Dog & & Niwatori & Chicken \\
& Kame & Tortoise & & Raion & Lion \\
& Kuma & Bear & & Simauma & Zebra \\
& Uma & Horse & & Zarigani & Crawfish \\
Man-made & Isu & Chair & & Airon & Iron \\
objects & Kago & Basket & & Enpitu & Pencil \\
& Kasa & Umbrella & & Kutusita & Socks \\
& Koma & Top & & Rousoku & Candle \\
& Kutu & Shoes & & Tebukuro & Glove \\
\hline
\end{tabular}

APPENDIX B

Stimulus Set in Experiment 3

\begin{tabular}{clllll}
\hline & \multicolumn{2}{c}{ Short Word } & & \multicolumn{2}{c}{ Long Word } \\
\cline { 2 - 3 } \cline { 5 - 5 } Lategory & Word & Meaning & & Word & \multicolumn{1}{c}{ Meaning } \\
\hline Living things & Ari & Ants & & Daikon & Japanese white radish \\
& Buta & Pig & & Gokiburi & Cockroach \\
& Hebi & Snake & & Hukurou & Owl \\
& Inu & Dog & & Koorogi & Cricket \\
& Kame & Tortoise & & Kosumosu & Cosmos \\
& Mugi & Barley & & Koumori & Bat \\
& Nasi & Pear & Ninzin & Carrot \\
& Neko & Cat & & Niwatori & Chicken \\
& Roba & Donkey & Ookami & Wolf \\
& Semi & Cicada & & Raion & Lion \\
& Uma & Horse & Uguisu & Bush warbler \\
& Yagi & Goat & Yamabuki & Kerria
\end{tabular}


APPENDIX B (Continued)

\begin{tabular}{|c|c|c|c|c|}
\hline \multirow[b]{2}{*}{ Category } & \multicolumn{2}{|c|}{ Short Word } & \multicolumn{2}{|r|}{ Long Word } \\
\hline & Word & Meaning & Word & Meaning \\
\hline \multirow{12}{*}{$\begin{array}{c}\text { Man-made } \\
\text { objects }\end{array}$} & Hari & Needle & Enpitu & Pencil \\
\hline & Hue & Pipe & Epuron & Apron \\
\hline & Isu & Chair & Houseki & Jewel \\
\hline & Kago & Basket & Huntou & Envelope \\
\hline & Kasa & Umbrella & Hunsen & Balloon \\
\hline & Koma & Top & Kutusita & Socks \\
\hline & Kutu & Shoes & Manaita & Chopping board \\
\hline & Mado & Window & Orugan & Organ \\
\hline & Nabe & Pot & Sinbun & Newspaper \\
\hline & Sori & Sledge & Tebukuro & Glove \\
\hline & Sumi & Charcoal & Youhuku & Western clothes \\
\hline & Tizu & Map & Zoukin & Dust cloth \\
\hline
\end{tabular}

(Manuscript received April 4, 2000;

revision accepted for publication February 6, 2001.) 